\title{
A IMPERATIVIDADE DO REORDENAMENTO DO ESPAÇO URBANO E OS CONTRIBUTOS AMBIENTAIS
}

\author{
THE URGE REORDERING OF THE URBAN SPACE AND ENVIRONMENTAL \\ BENEFITS
}

\begin{abstract}
JEFERSON DYTZ MARIN
Doutor em Direito - UNISINOS (RS). Mestre em Direito- UNISC (RS). Especialista em Direito Processual (UCS). Advogado. Professor do Mestrado em Direito da UCS - Universidade de Caxias do Sul. Professor de pós-graduação em diversas instituições de Ensino Superior no Rio Grande do Sul, Santa Catarina, Paraná e São Paulo. Membro do IEM Instituto de Estudos Municipais. Membro da ABDPC - Academia Brasileira de Direito Processual Civil. Coordenador das obras: "Jurisdição e Processo: efetividade e realização das pretensões materiais" e "Jurisdição e Processo II: racionalismo, ordinarização e reformas processuais", "Jurisdição e Processo III: estudos em homenagem ao Prof. Ovídio Baptista da Silva", todos pela Editora Juruá, de Curitiba-PR.

KAREN IRENA DYTZ MARIN

Mestre em Direito - UNISC (RS). Graduada em Direito na UFSM (RS). Professora da UCS - Universidade de Caxias do Sul. Coordenadora da Especialização em Direito Ambiental da UCS. Integrante do Conselho do Meio Ambiente da UCS - Universidade de Caxias do Sul.
\end{abstract}

\section{RESUMO}

A produção e o consumo hedonista desenfreado norteiam a vida humana na pós-modernidade e, paralelamente, a ocupação das cidades. Desconsidera-se, nessa esteira, a qualidade de vida, com esteio no avanço do capital e no desprezo aos recursos naturais. A sustentabilidade impõe limites temporais e espaciais na construção da sociedade e na ocupação das cidades. O Plano Diretor e a gestão ambiental urbana com propósitos isentos parecem constituir elementos essenciais na arquitetação de cidades sustentáveis, que integrem o homem a um meio qualitativo e ordenado, com escopo intergeracional. Parece, todavia, que o ponto nevrálgico da questão reside na mudança de paradigma cultural, externada na necessidade de superação do modo de vida individualista, que renuncia a inclusão do outro e elege o conforto e a proteção dos interesses particulares como prioridade inicial. Essa perniciosa conduta sufoca o viver integrado e impede a construção de uma cidade que tenha na cooperação, na inclusão e na valorização dos espaços público o esteio primordial.

Palavras-chave: meio ambiente; cidades; recursos; sustentabilidade.

\begin{abstract}
The production and the wild hedonist consumption guide the life human being in the after-modernity and, parallel, the occupation of the cities. It is disrespected, in this mat, the quality of life, with mainstay in the advance of the capital and the disdain to the natural resources. The sustainability imposes secular and space limits in the construction of the society and the occupation of the cities. The Managing Plan and the urban ambient management with exempt intentions seem to constitute essential elements in the construction of sustainable cities, that integrate the man to a qualitative and commanded way, with intergenerational target. It seems, however, that the crux of the matter lies in the cultural paradigm shift, externalized in the necessity of overcoming the individualistic way of life, which waives the inclusion of other and chooses the comfort and protection of interests as first priority. This pernicious conduct integrated live stifles and impedes the construction of a city that has on cooperation, inclusion and the enhancement of public spaces has been a mainstay paramount.
\end{abstract}

Keywords: environment; cities; resources; sustainability. 


\section{SUMÁRIO}

INTRODUÇÃO; 10 EQUILÍBRIO ENTRE CRESCER E PROTEGER: CONDIÇÃO INTERGERACIONAL; 2 DIREITO URBANÍSTICO E CRESCIMENTO ORDENADO CONCLUSÃO; REFERÊNCIAS.

\section{INTRODUÇÃO}

O capital é o grande impulsionador da atividade humana nas sociedades capitalistas. 0 homem está constantemente em busca de crescimento econômico e acúmulo de riqueza. A atividade produtiva, principalmente a baseada na industrialização, que prepondera após a Revolução Industrial, é o centro da atividade econômica das sociedades modernas.

O desenvolvimento econômico tem sido a tônica da sociedade globalizada, desconsiderando-se a qualidade de vida, mediante a justificação do capital e a apropriação indevida da natureza.

A concentração de riqueza, decorrência inevitável da sociedade capitalista contemporânea, obtida pelos que exploram com maior voracidade os recursos naturais, gera exclusão social e marginalização das comunidades pobres, impedidas de desenvolverem-se economicamente.

Os modelos de produção e desenvolvimento implantados pelos pioneiros da industrialização basearam-se em políticas de crescimento para o capital interno. A natureza e a conservação dos seus recursos disponíveis, como pressuposto para a manutenção da atividade econômica, não era vista com a devida e merecida importância, uma vez que sua abundancia e generosidade não alertavam para a possibilidade de virem a se tornar escassos.

A ideia de que os recursos naturais eram ilimitados e infinitos redundou em seu uso irracional, ignorando-se a capacidade de renovação e regeneração da natureza. Derrubando o paradigma e diante da percepção de que os ecossistemas são alterados pela ação humana, muitas vezes com consequência maléficas, a intervenção do homem na natureza passou a ser repensada, de maneira que fosse possível a realização das metas de desenvolvimento sem agressão aos ambientes naturais.

Surge, então, a necessidade de inventar modelos de produção que promovam o uso racional dos recursos naturais, utilizando-os sem esgotar a sua disponibilidade, para que subsistam em quantidade e qualidade suficientes ao suprimento das necessidades das gerações futuras. 
Conhecido como desenvolvimento sustentável, pensou-se num sistema apto a compatibilizar as atividades consumidoras de recursos naturais com a sua oferta natural, a fim de tornar o seu uso menos prejudicial ao equilíbrio ecológico.

As cidades também se inserem nesse contexto de desenvolvimento sustentável, na medida em que a preocupação ambiental urbana sugere cuidados na constituição dos espaços. A arborização, cada vez mais rara nos grandes aglomerados urbanos e os mecanismos de controle da poluição industrial são exemplos típicos das preocupações dessa cidade sustentável.

Mas o alcance de uma cidade sustentável vai muito além do atendimento dos requisitos daquilo que se pode designar de ambiente saudável, uma vez que reclama a construção democrática da ocupação dos espaços urbanos, não só com a preservação do meio ambiente, mas com a preservação em todos os pontos da cidade, viabilizando a localização e dimensionamento adequado das praças e parques, evitando assim a marginalização (ou o que se poderia chamar de exclusão ambiental) das populações periféricas.

\section{EQUILÍBRIO ENTRE CRESCER E PROTEGER: CONDIÇÃO INTERGERACIONAL}

O mundo capitalista orienta-se pela necessidade constante de produção, apresentado como objetivo final $o$ acúmulo de capital. 0 aspecto quantitativo interessa mais que 0 qualitativo, sendo irrelevante - ao menos na origem do sistema - a necessidade de preservação do ambiente e a noção de desenvolvimento sustentável.

A Revolução industrial esteve estreitamente ligada ao desenvolvimento do sistema capitalista, oferecendo significantes contribuições na medida em que propiciou as inovações tecnológicas necessárias ao aumento da capacidade produtiva das indústrias, na mesma proporção da crescente demanda imposta pela expansão populacional. A constante modernização dos parques industriais gerou condições de cada vez mais suprir o mercado com bens e produtos em quantidades mais do que suficientes para o entendimento das demandas.

Mas num sistema capitalista, o excesso também representa capital, razão pela qual os bens e produtos industrializados além das necessidades populacionais, passaram a ter seu consumo incentivo através de marketing mercadológico e propaganda. A partir desse momento passa-se a incentivar o consumo pelo consumo, cujo resultado é também a orientação dos 
processos produtivos a partir de estudos das demandas de mercado. Assim posiciona-se Eduardo Viola:

A resolução da crise ecológica é difícil e complexa. Os problemas ambientais são efeitos "inesperados" do modelo de desenvolvimento econômico dominante (capitalista-industrialista), que se "legitima" entendendo as demandas de consumo da população, e que por sua vez continua aumentando dentro de um planeta com capacidade de sustentação limitada ${ }^{1}$.

0 ideal de desenvolvimento adotado pelas nações interessadas em crescer economicamente a qualquer custo, principalmente no pó-guerra, como aceitação do sistema capitalista apoiado no liberalismo, consistiu no incentivo à produção e o consumo voltados apenas à geração de riqueza. Com isso, a necessidade constante do aumento da produção consequentemente fez crescer o consumo dos recursos naturais utilizados como matéria-prima nas indústrias, além de gerar poluição, explosão demográfica e sobrecarga dos ecossistemas. Héctor Ricardo Leis, ao estudar os efeitos do sistema neoliberalismo na esfera ambiental, observa:

O mercado prefere guiar-se por uma razão instrumental que, se transnacionaliza países e derruba fronteiras, não o faz para atender a valores universais ou para maximizar o aproveitamento dos recursos existentes em função do lucro e do poder dos principais agentes econômicos e políticos. Em outras palavras, a brutal expansão da economia mundial nas últimas décadas se fez por intermédio da desestruturação das economias nacionais, que transformou o mercado em responsável por um duplo processo de globalização econômica e ambiental, mas com sentidos opostos².

0 crescimento das economias mundiais aconteceu sem a preocupação com a questão ambiental, focada exclusivamente no resultado econômico das atividades produtivas. A ideologia neoliberal baseada na livre iniciativa da economia de mercado e na sua liberdade frente ao Estado provocou o crescimento econômico do mundo ocidental, originando regiões desenvolvidas, integradas pelos países ditos de primeiro mundo. Ocorre que estes países, concentrados no acúmulo de capital a qualquer custo, não economizaram no consumo e utilização dos recursos naturais como fonte para suas atividades produtivas. Ao concentrarem seus esforços no crescimento econômico, comprometeram-se pouco com a preservação do meio ambiente e com a exploração racional dos recursos ambientais. Prova disso é a recusa dos americanos em aderir ao Protocolo de Kyoto, documento assinado por vários países e que visa comprometê-los a diminuir os índices globais de emissão de poluentes na atmosfera terrestre.

\footnotetext{
${ }_{1}^{1}$ VIOLA apud LEIS, Héctor Ricardo (Org.). Ecologia e Política Mundial. Petrópolis: Vozes, 2001. p. 16.

${ }^{2}$ Idem, p. 26-7.

REDESG / Revista Direitos Emergentes na Sociedade Global - www.ufsm.br/redesg v. 1, n. 1, jan.jun/2012
} 
A ordem econômica brasileira funda-se na livre iniciativa e tem como um de seus princípios a livre concorrência. Adere, assim, às regras de mercado, que objetivam livre atuação dos agentes econômicos, com vistas ao crescimento econômico.

0 pós-guerra e o neoliberalismo dos anos 80 disseminaram pelo mundo a ideia de que 0 crescimento econômico e a produção de riqueza seriam requisitos do progresso mundial, partindo do pressuposto de que, quanto maior a liberdade do mercado para fazer circular a riqueza, maior o padrão de vida do povo. Tal pensamento serviria até como forma de consolidação da democracia em termos econômicos. Ao adotar-se a teoria neoliberal sem as necessárias ponderações quanto a seus efeitos, confere-se aos detentores do poder econômico a prerrogativa de oprimir os excluídos, o que conforta a tese que exclui do sistema neoliberal o progresso social.

É uma característica da ciência contemporânea e ênfase nos aspectos quantitativos e o seu desprezo pelos qualitativos, quando são justamente estes os mais essenciais. A própria vida se caracteriza pela sua essencialidade qualitativa, como o são a busca de bem-estar coletivo ou de felicidade individual (ou qualquer outro critério que se tome como motivador, em última instância das ações individuais ou coletivas). A constante busca pela quantitividade resulta não raras vezes na renúncia a certos elementos que garantem a qualidade de vida do homem, como o são o meio ambiente saudável e uma sociedade sem miséria.

Em economia, ao falar-se em desenvolvimento e crescimento, corre-se o risco de na maioria das vezes tomar ambos os conceitos por equivalentes, dando a impressão de representarem a ideia de evolução, melhoria, ou prosperidade. Embora reflitam objetivos comuns, o desenvolvimento econômico abriga a realização de metas muito mais abrangentes, enquanto que o crescimento econômico limita-se a alcançar um dos objetos daquele outro, a produção de capital e riqueza.

A Constituição Federal, ao disciplinar a ordem econômica e financeira, alicerçou-a em vários princípios, dentre os quais cabe destacar o da livre concorrência e o da defesa ao meio ambiente. ${ }^{3} \mathrm{O}$ primeiro ligado à livre iniciativa, decorre da ideia de Estado mínimo, pregado pelo liberalismo econômico.

0 mercado exige competitividade de preços. A indústria utiliza como matéria-prima, quase na sua totalidade, recursos naturais, sendo o custo da sua obtenção o fator determinante

\footnotetext{
${ }^{3}$ Ver: CANOTILHO, José Joaquim Gomes. Direito constitucional e teoria da constituição. 4. ed. Coimbra: Coimbra, 2000.

REDESG / Revista Direitos Emergentes na Sociedade Global - www.ufsm.br/redesg v. 1, n. 1, jan.jun/2012
} 
de um preço competitivo. Os sistemas produtivos raramente internalizam os custos ambientais da produção. Veja-se a observação de Dennis Kinlaw:

\begin{abstract}
Um fator a contribuir com nossa falta de atribuição de custos ao uso comercial do meio ambiente é que os indicadores econômicos que usamos não consideram o meio ambiente. Não acompanhamos nem reportamos como notícias econômicas as informações sobre perda da camada superficial do solo, redução de índices de pesca de florestas antigas, uso de energia e outras do gênero. Precisamos enfatizar a necessidade de atribuição de valor ao imput do meio ambiente, e a maneira mais universalmente reconhecida de ser atribuir valor é pela atribuição de preço. Ar, terra, água e recursos não-renováveis precisam ser valorizados em relação à sustentação do meio natural. Os muitos serviços prestados pelo meio ambiente não são gratuitos ${ }^{4}$.
\end{abstract}

A produção baseada num sistema econômico preocupado apenas com o lucro, ao ignorar o custo ambiental do processo produtivo, causa desequilíbrios de toda ordem, uma vez que superada a ideia de infinitude dos recursos naturais, sua utilização irracional é maléfica ao meio ambiente. Referido custo, embora não absorvido pelas indústrias e seus produtos, é suportado pelo meio ambiente e repassado à sociedade, que acaba pagando um preço caro, qual suja a falta de condições para buscar o desenvolvimento econômico completo a que tem direito. Uma produção economicamente barata, que não absorve o valor dos recursos naturais utilizados, reserva um custo social e ambiental elevado. A necessidade de preços baixos e competitivos impede a consideração do custo ambiental da produção, que mais cedo ou mais tarde será suportado pela sociedade.

Ramón Martín Mateo posiciona-se da seguinte forma quanto à fixação de preços competitivos à custa da exploração ambiental:

La teoria del valor y la lógica espontánea de los mecanismos de mercado como sistema de optimación de las decisiones económicas constituyen piedras angulares del sistema económico occidental, respondiendo a su filosofia basica centrada en la libertad y el pluralismo. En este contexto la utilización de los recursos naturales se apoya simplemente en la fijación de precios competitivos cuando éstos son escasos y se apropian privadamente. En la economía liberal tiene difícil encaje la instrumentación de medidas limitadoras de la denunciada exaustación de los recursos se los precisos no se sensibilizan, como es normal, ante fronteras de escasez que todavía aparecem distantes ${ }^{5}$.

A regulamentação e a condução da economia apenas pelas regras de mercado, como a livre concorrência, traz como consequência a falta de preocupação por morte dos agentes econômicos, com os resultados socioambientais de suas atividades. O modelo de produção

\footnotetext{
${ }^{4}$ KINLAW, Denis C. Empresa Competitiva e Ecológica: desempenho sustentável na era ambiental. São Paulo: Markon Books, 1997. p. 95.

${ }^{5}$ MATEO, Ramón Martín. Tratado de derecho ambiental. Madrid: Editoral Trivium. 1991. p. 45.

REDESG / Revista Direitos Emergentes na Sociedade Global - www.ufsm.br/redesg v. 1, n. 1, jan.jun/2012
} 
baseado na geração de riqueza e no acúmulo de capital, conflita com a necessidade de avaliarem-se os reflexos do sistema econômico para a sociedade e o meio ambiente.

O crescimento econômico passou a impulsionar as regras de mercado, e as metas mundiais de constante crescimento, em todos os sentidos, realizado às custas do sacrifício ambiental, ignoram, seus efeitos destrutivos, sendo fruto da concepção equivocada de que a diversidade da natureza seria capaz de proporcionar o fornecimento infinito dos recursos naturais utilizados na atividade produtiva. É a compreensão de Francisco Brito:

Os modelos de sociedade das civilizações até nossos dias foram projetados pelo homem para acumular riquezas materiais, bens e serviços. A seu favor teve a ciência e a tecnologia, o que possibilitou-lhe adquirir novos conhecimentos e interferir progressivamente nos processo naturais, ocupando e usando a seu belprazer dos recursos naturais. Tinha-se em mente de que tais recursos eram infinitos ${ }^{6}$.

O conceito de desenvolvimento econômico, muito mais amplo, é aquele que propicia ao mesmo tempo a geração de riquezas, mas com vistas à melhoria da qualidade de vida, integrado à satisfação de necessidades coletivas, e não meramente individuais. Ao limitar sua produção com o capital, abandona aspectos mais importantes, como a sociedade e o meio ambiente. Causa a exploração irracional dos recursos naturais, gerando poluição e desequilíbrio ambientais, além de miséria, pobreza e exclusão social.

A economia do desenvolvimento, apesar de voltada ao crescimento econômico, como um dos seus objetos, não pode ser vista como um sistema dissociado do meio ambiente, pois não existe atividade humana sem água, ar, solo, ou sem a utilização de qualquer outro recurso natural. 0 desenvolvimento econômico pressupõe a interação entre atividade humana e natureza, uma vez que toda geração de riqueza passa pela transformação de energia e consumo de recursos naturais.

O desenvolvimento econômico, como princípio da ordem econômica constitucional, é aquele que busca dentre outros fatores, a melhoria da qualidade de vida em todos os seus aspectos, a igualdade de condições, índices de educação satisfatória, trabalho digno e oportunidades para toda a coletividade.

A Constituição Brasileira de 1988 introduziu a questão ambiental na ordem econômica, de modo que as atividades econômico-produtivas sejam desenvolvidas levando-se em consideração a proteção aos recursos naturais e aos ecossistemas, evitando-se assim o

${ }^{6}$ BRITO, Francisco A.; CÂMARA, João B. D. Democratização e gestão ambiental: em busca do desenvolvimento sustentável. Petrópolis: Vozes, 1998. p. 64.

REDESG / Revista Direitos Emergentes na Sociedade Global - www.ufsm.br/redesg v. 1, n. 1, jan.jun/2012 
desequilíbrio ecológico. Além disso, ao determinar a proteção ambiental, criou capítulo no qual garantiu a todos o direito a um meio ambiente ecologicamente equilibrado.

Falar em desenvolvimento econômico exige a conjugação de vários fatores, como o crescimento econômico e a garantia deste mesmo crescimento para as futuras gerações somente possivel mediante a proteção ambiental, bem como a criação de condições sociais para que os homens possam viver com dignidade, qualidade, e de maneira saudável.

Insere-se, nesse contexto, a ideia de desenvolvimento sustentável, como aquele que preconiza a busca pelo crescimento econômico de maneira racional, não separada do respeito à natureza e à sociedade como um todo, para assim atingir-se o que se pode realmente entender por desenvolvimento econômico. Assevera Francisco Brito:

Contudo, observa-se que a tendência da nova concepção de meio ambiente é que novos paradigmas de desenvolvimento contemplem equidade social, econômica, política e meio ambiente, com vistas a conciliar as necessidades econômicas à disponibilidade limitada dos recursos naturais e sua proteção. Nesse sentido, prevê-se que cada vez mais os novos paradigmas deverão compatibilizar os interesses econômicos e sociais com a proteção ambiental dentro de um processo de desenvolvimento sustentável, transformando o meio ambiente em fator de desenvolvimento sem, contudo, causar danos ambientais ${ }^{7}$.

Não se pode deixar de assinalar o aspecto do desenvolvimento humano, que ao ser estudado de forma coadunada ao desenvolvimento econômico, sugere este como espécie da qual aquele é o gênero. 0 primeiro como conceito mais amplo revela que toda atividade humana tem como fim último o ser em si mesmo. Logo, a variável econômica é apenas um pressuposto para otimizar a qualidade da vida segundo bens e produtos que expressam valor econômico.

Uma nação rica economicamente não alcança desenvolvimento satisfatório se nela existir parcela da população em condições sub-humanas e sem possibilidades de desenvolver-se socialmente, bem como se o meio ambiente estiver degradado pelo esgotamento da capacidade dos ecossistemas. O simples acúmulo de capital não traduz desenvolvimento. Este somente realiza-se mediante a conciliação do crescimento econômico com a melhoria da qualidade de vida de todos os atingidos, direta ou indiretamente, pela atividade econômica.

Por fim, em termos econômicos, observa-se que desenvolver é crescer, mas crescer nem sempre dá ideia de desenvolvimento. O desenvolvimento integrado da economia e do ser humano, com vistas à manutenção de um ecossistema equilibrado, traz à tona a idéia de sustentabilidade.

${ }^{7}$ Idem, p. 30.

REDESG / Revista Direitos Emergentes na Sociedade Global - www.ufsm.br/redesg v. 1, n. 1, jan.jun/2012 
A crise ambiental aparece hoje como desafio a ser enfrentado pelo homem, a fim de poder vencer a grande empreitada de tutela do meio ambiente e recuperar suas características principais, quais sejam, a diversidade e o equilíbrio entre qualidade e quantidade dos recursos naturais. A terra é o habitat originário e comum do homem e de todos os demais seres que com ele habitam. A vida humana não subsiste senão pelo consumo dos bens da natureza, imprescindíveis à existência das gerações presentes e futuras.

A apropriação dos recursos naturais pelo homem deu-se numa escala progressiva ao longo de sua existência. Partindo-se das sociedades primitivas, consumia apenas o necessário para viver. Com o início da produção manufaturada, sua utilização ainda era racional, pois realizada em ritmo lento, de acordo com as técnicas até então criadas. As mudanças ocorridas com o surgimento das indústrias, a partir do século XIX, ocasionaram a concentração da produção em grandes fábricas, com aumento no consumo dos recursos naturais, estabelecendo uma relação de dominação do homem sobre a natureza.

A razão da crise ambiental está na verdadeira disputa existente entre o homem e a natureza, em torno da apropriação dos recursos limitados, exigidos para a satisfação de necessidades humanas ilimitadas, fruto da constante evolução de sociedades consumistas e de ideias de desenvolvimento econômico baseado no acumulo de capital.

O planejamento de estratégias para a exploração dos recursos naturais é condição para chegar-se ao desenvolvimento sustentável, adequando às atividades econômicas e a real capacidade da natureza de suportar a intervenção humana, considerando ainda a manutenção dessa mesma capacidade para os tempos vindouros.

A exploração racional dos recursos ambientais constitui ponto crucial, senão o principal, na busca da sustentabilidade, missão que não mais permite considerar como limitados os bens da natureza. Os novos modelos de produção a serem desenvolvidos devem adotar tecnologias limpas e eficientes, evitando o desperdício de matéria-prima, o consumo desnecessário de recursos naturais, bem como daqueles que demandam técnicas poluentes para sua industrialização, gerando poluição.

Mais do que isso, faz-se necessário conservar a diversidade natural dos ecossistemas a fim de permitir a recuperação dos mesmos, até então degradados pela ação antrópica, de maneira a realizar-se a reposição dos recursos naturais pela sua renovação e regeneração, a fim de que tornem-se disponíveis às gerações futuras. Tratando deste aspecto, escreve Paulo Affonso Soares Pereira: 
A sustentabilidade ecológica é a manutenção da base física, os estoques de recursos naturais, "apesar" do processo de "desenvolvimento". Para sua implementação dois critérios operacionais devem ser aplicados: o primeiro, a reposição dos recursos naturais "renováveis" a uma taxa superior à da sua utilização; e o segundo critério, para os não renováveis, consiste em dosar o uso do recurso de forma que antes de seu esgotamento total haja um sucedâneo, viável, em uso ${ }^{8}$.

0 artigo 186 da Constituição Federal, talvez seja o dispositivo legal que expresse de forma mais clara a ideia de sustentabilidade. Ao tratar da função social da propriedade coloca como requisito para a concretização desta, dentre outros, o da utilização adequada dos recursos naturais disponíveis e a preservação do meio ambiente.

A realização do ideal do desenvolvimento sustentável não compete a um órgão ou setor específicos da comunidade. Ao contrário, é tarefa que exige a participação de toda a sociedade, pois não depende de ações isoladas, mas da tomada de decisões por parte dos órgãos competentes e da conscientização da população da necessidade de buscar alternativas práticas para a exploração sustentável dos recursos naturais. Nesse sentido, ensina Francisco Brito:

Faz-se necessário a construção de uma nova sociedade para uma nova realidade institucional do setor ambiental, de maneira a corrigir os desvios do passado em relação ao desrespeito com o meio ambiente, e dar respostas mais adequadas aos problemas ambientais pontuais e globais. A questão ambiental deve ser cuidada com a participação da sociedade como um todo: governo e povo trabalhando unidos por uma gestão ambiental sustentável para resolver conflitos de interesses divergentes entre proteção ambiental e desenvolvimento sustentável ${ }^{9}$.

O desenvolvimento sustentável, abrigando pela Declaração do Rio, de 1992, objetiva propiciar a todos o direito ao desenvolvimento, mas de maneira que este seja exercido de forma tal que atenda as necessidades atuais, respeitando as demandas das gerações futuras. 0 princípio $4^{\circ}$ da Declaração do Rio afirma que a proteção ao meio ambiente deve integrar o processo de desenvolvimento, a fim de alcançar o desenvolvimento sustentável, tarefa que conta com instrumentos como o Estatuto de Impacto Ambiental, criado pelo Poder Público e útil no planejamento de atividades com potencial de dano ao meio ambiente.

A luta pelo desenvolvimento sustentável iniciou, cabendo aos ambientalistas e o poder público definir políticas públicas e fazer cumprir as leis ambientais e as propostas de

\footnotetext{
${ }^{8}$ PEREIRA, Paulo Affonso Soares. Rios, redes e regiões: a sustentabilidade a partir de um enfoque integrado dos recursos terrestres. Porto Alegre: AGE. 2000. p. 146.

9 BRITO, Francisco A.; CÂMARA, João B. D. Democratização e gestão ambiental: em busca do desenvolvimento sustentável. Petrópolis: Vozes, 1998. p. 46-7.

REDESG / Revista Direitos Emergentes na Sociedade Global - www.ufsm.br/redesg v. 1, n. 1, jan.jun/2012
} 
desenvolvimento que priorizem e racional utilização dos recursos naturais, tornando a sustentabilidade uma realidade futura, muito embora uma utopia da atualidade.

\section{DIREITO URBANÍSTICO E CRESCIMENTO ORDENADO}

A noção de sustentabilidade vem desde os primeiros embates na seara ambiental, quando então se viu que, se a exploração dos recursos naturais seguisse no ritmo que se apresentava fatalmente seu esgotamento adviria em pouco tampo. Por outro lado, também se percebeu que não era razoável e nem possível que se abrisse mão do progresso, da tecnologia e do conceito de sociedade de consumo - consequência que logicamente adviriam de uma suspensão total do consumo em massa de recursos naturais, se esta fosse possível.

É impossível manter o mesmo nível de produção para toda a humanidade sem que haja um colapso ecológico, uma vez que a capacidade cientifica e tecnológica de processar as matérias é infinitamente superior à capacidade que a natureza tem de se regenerar ou de ofertar matéria prima para seu processamento. 0 mais incrível é que este enunciado é válido tanto para os processos individuais de modelo de desenvolvimento, como para os modelos coletivistas ou de socialização dos meios de produção.

Logo, a solução deveria estar na razoabilidade e na moderação do consumo dos recursos naturais, bem como na minimização do impacto das atividades humanas sobre o meio ambiente.

O tempo demonstrou que, se essa política não foi eficaz no sentido de garantir níveis satisfatórios de alteração ambiental, pela menos deu fôlego à indústria para que a mesma buscasse alternativas que permitissem sua continuidade. Carros mais econômicos, eletrodomésticos mais eficazes, reciclagem de materiais, controle de emissões poluentes, saneamento adequado, transportes racionais, áreas verdes urbanas - são os produtos da noção de sustentabilidade.

No Brasil, a Constituição Federal, em seu artigo 225, demonstrou a preocupação do legislador com o uso racional dos recursos naturais, como garantia de uma vida saudável, impondo tanto ao Poder Público, como a todos os cidadãos, a preservação do meio ambiente, viabilizando um habitat ecologicamente equilibrado para as presentes e futuras gerações - falase já em um direito intergeracional. 0 dispositivo inova ao introduzir as gerações futuras não só como interessadas, mas como titulares de direitos em relação ao desenvolvimento. ${ }^{10}$

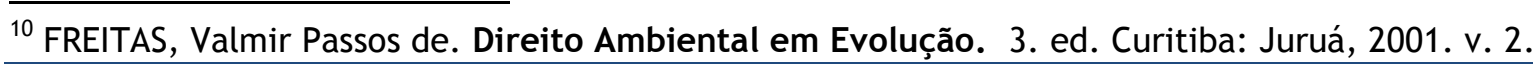

REDESG / Revista Direitos Emergentes na Sociedade Global - www.ufsm.br/redesg v. 1, n. 1, jan.jun/2012
} 
As mais modernas definições já incorporam a noção de desenvolvimento sustentável, corolário da evolução antes explorada.

Dinizar Becker, ao examinar a sustentabilidade enquanto novo (velho) paradigma do desenvolvimento regional aponta para o tipo de economia que assegurará um desenvolvimento adequado, sintonizado à ideia de ecologia profunda:

[...] uma possibilidade que, na verdade, é o outro lado da competitividade, e é o que the dá organicidade, e que denominamos de sustentabilidade. Sustentabilidade como reconhecimento das diversidades ambientais e culturais que se transformam em vantagens ou trunfos dos diferentes espaços e escalas geográficas e na sabedoria de como articular a autonomia, decorrente da diversidade com a unidade da sociedade nacional e/ou global (Becker, 1993. p. 137). Sustentabilidade compreendida como as múltiplas alternativas que cada localidade, região ou nação tem, pelas suas diferentes culturais e ambientais, de inserir-se no processo geral potencializando seus recursos. ${ }^{11}$

Ou seja: a sustentabilidade é um conceito fortemente baseado na noção do razoável, oposto à exploração plena e o abuso.

A noção de dignidade está intrinsecamente ligada à ideia de sustentabilidade, que é um tanto subjetiva, e nem mesmo seus primeiros defensores a definem claramente. Todavia, sabese que a noção de dignidade está intimamente vinculada, na cultura ocidental, ao respeito à individualidade.

Essa noção é fundamental, vindo logo no primeiro considerando da Declaração Universal dos Direitos Humanos: “Considerando que a reconhecimento da dignidade inerente a todos os membros da família humana e seus direitos iguais e inalienáveis é o fundamental da liberdade, da justiça e da paz do mundo".

Ingo Sarlet tece, a partir de Kant, mas com os temperos que a noção moderna de ecologia empresta, rechaçando a ideia de antropocentrismo, a seguinte definição acerca da dignidade do homem:

[...] sempre haverá como sustentar a dignidade da própria vida de um modo geral, ainda mais numa época em que o reconhecimento da proteção do meio ambiente como valor fundamental indica que não mais está em causa apenas a vida humana, mas a preservação de todos os recursos naturais, incluindo todas as formas de vida existentes no planeta, ainda que se possa argumentar que tal

11 BECKER, Dinizar Fermiano. SUSTENTABILIDADE: Um novo (velho) paradigma de desenvolvimento regional. In: BECKER, Dinizar Fermiano (Org.). Desenvolvimento sustentável. Necessidade e/ou possibilidade? Santa Cruz do Sul: EDUNISC, 2002. p. 40.

REDESG / Revista Direitos Emergentes na Sociedade Global - www.ufsm.br/redesg v. 1, n. 1, jan.jun/2012 
proteção da vida em geral constitua, em última análise, exigência da vida humana e vida humana com dignidade. ${ }^{12}$

Veja-se que uma vida digna é algo extremamente complexo de ser definido e atingido. No contexto do presente trabalho, um meio ambiente que não agrida as pessoas é condição para a implementação da vida digna. Qual a dignidade de viver de desfrutar das benesses do capital, se o ar vem impregnado de eflúvios desagradáveis e até mesmo tóxicos, de petróleo, de fumaça...? E a dignidade das populações miseráveis que devem viver consumindo águas de fumaça...? E a dignidade das populações miseráveis que devem viver consumindo águas sem tratamento, vizinhando com o esgoto a céu aberto e com os lixões?

Mesmo que não se direcione para esse enfoque negativo, muito é necessário para uma vida digna. Que é o ser urbano sem moradia, saneamento ambiental, infraestrutura urbana, transporte e serviços públicos, trabalho e lazer?

Se a vida no meio urbano oferece certas comodidades, também é de se reconhecer que nem todos a elas têm acesso! Vida saudável, entretanto, é um conceito muito mais biológico que social ou jurídico. Está ligado ao bem-estar, mas no enfoque restrito ao adequado exercício das funções vitais. A primeira premissa é a alimentação adequada, que deve incluir todos os nutrientes necessários ao pleno desenvolvimento do organismo humano; ar e água livres de poluentes; e destinação adequada dos desejos orgânicos.

Um ser humano mal alimentado fraqueja em seu sistema imunológico, que deixa o corpo vulnerável frente à ação de organismos nocivos, ou, em nível celular ou mesmo atômico, de seus elementos constituintes. Certamente, a fome é a maior das degradações ambientais do planeta!

0 ar poluído é o vetor de elementos químicos estranhos à sua composição natural, que, ingressando no sistema respiratório, acabem por induzir alterações celulares ou mesmo, simplesmente por corroer os pulmões, seus acessórios e por fim o corpo; a água, em tudo, da mesma forma, Ambos, por fim, podem transportar os agentes orgânicos vivos que causam as mais variadas espécies de doenças.

Mas talvez o grande mal da pós-modernidade não esteja no corpo. A velocidade da pósmodernidade e a competitividade do mercado gera tensão ao homem, sempre incitado a produzir mais e mais, a não fraquejar nesse afã, a não parar, a tornar-se cada vez mais maquinal, o que já era previsto por Charles Chaplin como a nova doença do ser humano.

\footnotetext{
${ }^{12}$ SARLET, Ingo Wolfgang. Dignidade da pessoa humana e direitos fundamentais. Porto Alegre: Livraria do Advogado, 2001. p. 35.

REDESG / Revista Direitos Emergentes na Sociedade Global - www.ufsm.br/redesg v. 1, n. 1, jan.jun/2012
} 
Menos de quatro por cento da população mundial consome $80 \%$ dos bens e mercadorias produzidos pelo homem, menos de $25 \%$ da população do globo vive nos países ricos e consumindo mais de $75 \%$ da energia, que rejeita em seus guetos os excluídos do desenvolvimento, entre os quais 10 a 20\% são desempregados. ${ }^{13}$ Essa estatística traz a constatação de que, a exclusão social, fruto do acesso limitado aos bens de consumo, gera a ilação de que os detentores do capital e as potências mundiais são os principais responsáveis pela degradação do ambiente, através de um desenvolvimento "estreito e predatório". ${ }^{14}$

É de se notar que o stress, palavra da língua inglesa que significa pressão, mas usada comumente para designar uma de suas consequências, a estafa mental, tem sido associada a varias doenças - trata-se dos males psicossomáticos. Se grandes cientistas conseguiram prolongar a vida humana e possibilitaram a proliferação indiscriminada da espécie, agora preocupam-se em como frear tudo isso... Os remédios comuns podem curar uma outrora fatal tuberculose, os médicos conseguem salvar doentes de câncer, mas ainda não se descobriu a cura da tristeza. $\mathrm{E}$ a estrutura dos grandes aglomerados urbanos está diretamente ligada a essa triste nostalgia que ressai dos tempos modernos. Essa crise da pós-modernidade e a ideia de desenvolvimento dissociada do humano e a ser entregue às futuras gerações é descrita por Morin:

\begin{abstract}
A idéia de desenvolvimento continua ainda tragicamente subdesenvolvida porque presa à racionalidade econômica. Essa idéia de desenvolvimento foi e é cega às riquezas culturais das sociedades arcaicas ou tradicionais que só foram vistas através das lentes economistas e quantitativas. Ela reconheceu nessas culturas apenas idéias falsas, ignorâncias, superstições, sem imaginar que continham instituições profundas, saberes milenarmente acumulados, sabedorias da vida e valores éticos atrofiados entre nós. Fruto de uma racionalização ocidentalcêntrica, o desenvolvimento foi igualmente cego ao fato de que as culturas de nossas sociedades desenvolvidas comportam dentro delas, como toas as culturas, mas de formas diferentes, ao lado de verdades e virtudes profundas (entre as quais a da racionalidade, autocrítica que permite perceber as carências e falhas de nossa própria cultura), idéias arbitrárias, mitos sem fundamentos (como ilusão de termos chegado ao auge da racionalidade e de sermos os depositários exclusivos desta), cegueiras terríveis (como as do pensamento fragmentado, compartimento, redutor e mecanicista). ${ }^{15}$
\end{abstract}

13 BECKER, Dinizar Fermiano. SUSTENTABILIDADE: Um novo (velho) paradigma de desenvolvimento regional. In: BECKER, Dinizar Fermiano (Org.). Desenvolvimento sustentável. Necessidade e/ou possibilidade? Santa Cruz do Sul: EDUNISC, 2002. p. 63.

${ }^{14}$ Idem.

${ }^{15}$ apud Idem. p. 64.

REDESG / Revista Direitos Emergentes na Sociedade Global - www.ufsm.br/redesg v. 1, n. 1, jan.jun/2012 
O constituinte brasileiro preocupa-se com essa tendência do mundo moderno, e tentou abrir as portas para uma vida sadia de diversas formas; entre elas, pela garantia de lazer e recreação.

Entretanto, a grande empreitada da pós-modernidade é alcançar efetividade para os direitos fundamentais, dentre os quais, se põe o direito ao ambiente sadio. A Carta Política, posta pelo constituinte de 88 como a panaceia para todos os males sociais do país, não alçou o voo desejado e, já em seu nascedouro, lastreou declarações que sugeriam a ingovernabilidade na hipótese de seu cumprimento.

Isso gerou a triste ideia de que a Constituição, como carta de princípios, deve ser percebia como um ideal a ser seguido, com a gradativa implementação dos direitos nela tutelados. Os direitos sociais, individuais, ambientais, foram, paulatinamente, relegados ao ostracismo governamental, reclamado a permanente e vigilante atuação dos movimentos ambientais para o forçoso cumprimento dos pactos constitucionais que deveriam ser naturalmente implementados.

Assim, o melhor caminho para uma vida saudável, compreendidos os aspectos físico e psíquico, ainda é um adequado equilíbrio entre o trabalho e a sociedade, qualificados por um suporte indispensável advindo da dignidade, compreendido o direito ao alimento, à água e à atmosfera despoluída.

Atualmente $61 \%$ da área de terra do mundo está sendo modificada pela ação do homem para suprir a demanda de recursos de aproximadamente $2 \%$ dos $61 \%$ que correspondem às terras ocupadas por cidades, que abrigam $42 \%$ da população mundial. ${ }^{16}$

De acordo com este panorama, pode-se verificar o impacto do ambiente construído em relação ao ambiente natural, e constar que uma parte significativa dos desequilíbrios que ocorrem no mundo tem origem urbana. As cidades, como protagonistas de impactos ambientais, caracterizam-se pela concentração espacial de oportunidades, como mão de obra, meios de produção, distribuição e consumo, serviços, empregos, informação e consequentemente pelo crescimento populacional e desafios dessa concentração.

Mas o que é, enfim, uma cidade? Os estudiosos que abordam o tema ponderam que vários aspectos devem ser tomados em considerações. Júlio César Rocha conseguiu assim sintetizar essa multiplicidade:

\footnotetext{
${ }^{16}$ LYLE, J. T. Regenerative desing for sustainable development. New York: John Wiley \& Sons, 1994.

REDESG / Revista Direitos Emergentes na Sociedade Global - www.ufsm.br/redesg v. 1, n. 1, jan.jun/2012
} 
A cidade é o lugar geográfico onde se manifestam, de forma concentrada, as realidades sociais, econômicas, políticas e demográficas, de um território; ainda, o espaço contínuo ocupado por um aglomerado humano considerável, denso e permanente, cuja evolução e estrutura (física, social e econômica) são determinadas pelo maio físico, pelo desenvolvimento tecnológico e pelo modo de produção do período histórico considerado e cujos habitantes têm status urbano. Como vimos, fixar o conceito de cidade não é tarefa fácil, principalmente porque se pode tomar como base uma diversidade de abordagens. A cidade pode ser compreendida com fundamento: a) no conceito da sociologia urbana (cidade como "situação humana", "uma organização geral da sociedade", "centro de consumo de massa" ou "fábrica social"; b) no conceito demográfico e quantitativo (baseado no número de habitantes do núcleo urbano); c) no conceito econômico (conjunto de subsistemas administrativos, comerciais, industriais e socioculturais no sistema nacional geral); d) e no conceito jurídico político (a idade consiste em um núcleo urbano, sede do governo municipal). ${ }^{17}$

Os conceitos demográfico e econômico não servem para definir as cidades brasileiras, que são conceitos jurídicos-políticos, que se aproximam da concepção das cidades como conjuntos de sistemas. O centro urbano no Brasil só adquire a categoria de cidade quando o eu território se transforma em Município. Cidade, no Brasil, é um núcleo urbano qualificado por um conjunto de sistema político-administrativo, econômico não agrícola, familiar e simbólico como sede do governo municipal, qualquer que seja a sua população. Contudo, a característica marcante da cidade do Brasil consiste no fato de ser um núcleo urbano, que abriga a organização política local.

Enfim, no ponto de vista urbanístico, um centro populacional assume características de cidade quando possui dois elementos essenciais: (a) as unidades edilícias, ou seja, o conjunto de edificações em que os membros da coletividade moram ou desenvolvem suas atividade produtivas, comerciais, industriais ou intelectuais; (b) os equipamentos públicos, ou seja, os bens públicos e sociais criados para servir às unidades edilícias e destinados à satisfação das necessidades de que os habitantes não podem prover-se diretamente e por sua própria conta (estradas, ruas, praças, parques, jardins, canalização subterrânea, escolas, igrejas, hospitais mercados, praças de esportes enfim.).

Nessa ótica construtivista, para alcançarem-se as características da cidade sustentável, necessário definir o que se define por espaço, urbanização, urbanificação e urbanismo.

\footnotetext{
${ }_{17}$ ROCHA, Júlio César. Função ambiental da cidade: direito ao meio ambiente urbano ecologicamente equilibrado. São Paulo: Juarez de Oliveira, 1999. p. 4-5.

REDESG / Revista Direitos Emergentes na Sociedade Global - www.ufsm.br/redesg v. 1, n. 1, jan.jun/2012
} 
O espaço, como define Manuel Castells, compreende a concepção física e social. $\mathrm{Na}$ primeira, tem-se que não pode ser definido fora da dinâmica da matéria e na segunda, imprescindível a análise das práticas sociais. "Espaço é tempo cristalizado". ${ }^{18}$

Para Castells, do ponto de vista da teoria social:

[...] espaço é o suporte material de práticas sociais de tempo compartilhado. Imediatamente acrescendo que qualquer suporte material tem sempre sentido simbólico. Por práticas sociais de tempo compartilhado, refiro-me ao fato de que o espaço reúne essas práticas que são simultâneas no tempo. É a articulação material dessa simultaneidade que dá sentido ao espaço vis-à-vis a sociedade. Tradicionalmente, essa idéia foi assimilada à contigüidade. Mas é essencial que separemos o conceito básico de suporte material de práticas simultâneas da noção de contigüidade, a fim de justificar a possível existência de suportes materiais de simultaneidade que não dependam de contigüidade física, visto que é exatamente este o caso das práticas sociais predominantes na era da informação. ${ }^{19}$

Dessa forma, a noção de espaço não pode vir dissociada da idéia de sociedade, da formação demográfico-cultural das cidades, da ideia de meio ambiente, de acesso aos direitos sociais, de constituição humana e enfim, da rede que envolve a informação e a interdependência da sociedade pós-moderna.

Urbanização é o termo utilizado para designar o fenômeno via do qual a população urbana cresce em ritmo superior à população rural. Não se trata apenas do crescimento das cidades, mas de um processo de concentração populacional em zona urbana. "A sociedade em determinado país reputa-se urbanizada quando a população urbana ultrapassa 50\%”. ${ }^{20}$

Hoje, é razoável que se reconheça que todo o assim chamado "primeiro mundo" é urbanizado. Todavia, mesmo países como o Brasil, classificados como emergentes, já de há muito ultrapassaram a barreira da maioria urbana.

Logo, há que se admitir que a urbanização é fenômeno moderno, produto da sociedade industrializada e que atinge em cheio o espaço urbano brasileiro, onde predomina a especulação imobiliária e a favelização, sem falar-se na ocupação e degradação de áreas ambientais, como as áreas de mananciais. Neste sentido, a ordem jurídica pode significar uma alternativa em benefício da coletividade, no estabelecimento de uma política urbana é social, na defesa do

${ }_{18}$ CASTELLS, Manuel. A sociedade em rede. A era da informação: economia, sociedade e cultura. Traduzido por Roneide Venâncio Majer. v. 2. 3. ed. São Paulo: Paz e Terra, 2000. p. 435.

${ }^{19}$ Idem. p. 436.

${ }^{20}$ SILVA, José Afonso da. Curso de direito constitucional positivo. 9. ed. rev. atual. São Paulo: Malheiros, 1998. p. 26.

REDESG / Revista Direitos Emergentes na Sociedade Global - www.ufsm.br/redesg v. 1, n. 1, jan.jun/2012 
meio ambiente e do direito à cidade, ou simplesmente uma forma instrumental de segregação e de dominação no território urbano, como historicamente observa-se.

Quando a urbanização atinge níveis extremos, os problemas que dela decorrem acabam por determinar a necessidade da intervenção estatal para que seja preservada a ordem e a habitabilidade da cidade. Dá-se então "a unificação, processo deliberado de correção da urbanização, consistente na renovação urbana, que é a reurbanização, ou na criação artificial de núcleos urbanos, como as cidades novas da Grã-Bretanha e Brasília”. ${ }^{21}$

O termo 'urbanificação' foi cunhado por Gaston Bardet para designar “a aplicação dos princípios do urbanismo, advertindo que a urbanização é o mal, a urbanização é o remédio”. ${ }^{22} 0$ urbanismo surgiu como técnica e ciência, a fim de suprir as falhas de organização do espaço urbano, abrangendo da disposição do sítio os recuos, arruamento, zoneamento por atividades ou finalidade, taxa de ocupação do solo e outros conceitos que não podem ser desconsiderados para que a cidade cresça de forma ordenada.

Nesse contexto, a definição de urbanismo vazada por Antônio Bezzera Baltazar afigurase adequada:

[...] o urbanismo é uma ciência, uma técnica e uma arte ao mesmo tempo, cujo objetivo é a organização do espaço urbano visando ao bem-estar coletivo através de uma legislação, de um planejamento e da execução de obras públicas que permitam o desempenho harmônico e progressivo das funções urbanas elementares: habitação, trabalho, recreação do corpo e do espírito, circulação no espaço urbano. ${ }^{23}$

Ou seja, trata-se da normatização técnica e jurídica da distribuição das benfeitorias urbanas, mas destinada ao fim específico da funcionalidade, com o alcance da nova noção de "função sociais da cidade".

O Direito Urbanístico possui como objetivo direto a ordenação e planejamento dos espaços urbanos, ou seja, disciplina a atuação do Poder Público para a utilização dos espaços habitáveis. As normas e do adensamento das cidades. Na verdade, ele não se restringe à cidade, mas alcança também a relação desta com o campo e com as áreas que a cercam - daí ser aceito como o direito disciplinador dos espaços habitáveis.

Com essas definições básicas, fica aplainado o caminho para que se adentre no campo do Direito Ambiental aplicado à cidade.

\footnotetext{
${ }^{21}$ Idem, p. 27.

22 Idem.

${ }^{23}$ Idem. p. 30.
}

REDESG / Revista Direitos Emergentes na Sociedade Global - www.ufsm.br/redesg v. 1, n. 1, jan.jun/2012 
Mas é necessário que a premissa básica da sustentabilidade urbana seja a desaceleração do processo de urbanização. Muito se falou em políticas de contenção do êxodo rural - hoje, aliás, assunto bem menos em voga do que há dez anos. 0 processo de migração das populações rurais para a periferia das cidades criou aqueles notórios bolsões de miséria que, com sua simples presença, acabam por provocar a inviabilidade da organização das cidades. Isso é consequência do que Manuel Castells chama de espaço de fluxos, "que determina a organização espacial das elites gerenciais dominantes (e não classes) que exercem as função direcionais em torno das quais o espaço é articulado". ${ }^{24}$

Para Castells, a teoria do espaço dos fluxos,

[...] parte de suposição implícita de que as sociedades são organizadas de maneira assimétrica em torno de interesses dominantes específicos a cada estrutura social. 0 espaço de fluxos não é a única lógica espacial de nossas sociedades. É, contudo, a lógica espacial dominante porque é a lógica espacial dos interesses/funções dominantes em nossa sociedade. Mas essa dominação não é apenas estrutural. É estabelecida, na verdade, concebida, decidia e implementada por atores sociais. Portanto, a elite empresarial tecnocrática e financeira que ocupa as posições de liderança em nossas sociedades também terá exigências espaciais específicas relativas ao suporte material/espacial de seus interesses e práticas. ${ }^{25}$

O que Castells propõe, em verdade, é a democratização do espaço urbano, com o rompimento da lógica dominante do que chama de "elite empresarial tecnocrática e financeira". 0 poder financeiro, mediante a especulação imobiliária e os investimentos de massa é o que determina o ordenamento urbano na atualidade. São várias as consequências dessa realidade de fluxo de espaço, das quais, se destaca, a inumação das áreas verdes e parques e a marginalização das populações de baixa renda à periferia, à encostas dos morros e às zonas de risco em geral. Os centros de consumo de massa, fruto do poder financeiro, acabaram com as economias familiares de bairro, o que redunda, em última análise, em exclusão e concentração de riqueza.

São milhões de pessoas subempregadas nos centros urbanos, que viajam dezenas de quilômetros para poder chegar de suas casas a seus locais de trabalho. Esse fluxo de trafégo torna qualquer cidade caótica. Por outro lado, o ritmo da ocupação do solo é muito superior ao da instalação de benfeitorias urbanas que concedem a uma área o mínimo de organização.

${ }^{24}$ CASTELLS, Manuel. A sociedade em rede. A era da informação: economia, sociedade e cultura. Traduzido por Roneide Venâncio Majer. 3. ed. São Paulo: Paz e Terra, 2000. v. 2. p. 439.

${ }^{25}$ Idem, p. 439-40.

REDESG / Revista Direitos Emergentes na Sociedade Global - www.ufsm.br/redesg v. 1, n. 1, jan.jun/2012 
Assim, formam-se as favelas, verdadeiras selvas urbanas, sem arruamento, sem rede de energia, sem reserva de áreas verdes, sem esgoto sanitário e nem água tratada; enfim, sem as menores condições de habitabilidade.

Esse quadro leva a muitos formadores de opinião afirmarem que os desafortunados que se dirigem para a periferia das cidades é que são os responsáveis pelo fenômeno da urbanização. Essa lógica demagógica, contudo, não se sustenta. Trata-se, na verdade, de uma resposta a uma maneira equivocada de tratar as necessidades do povo, é a vazão da concentração de riqueza e da exclusão urbana; e isso não é exclusividade do Brasil. A mecanização maciça da lavoura no Terceiro Mundo, a partir dos anos 70, deu um impulso vertiginoso ao processo de urbanização ao redor do globo, e no Brasil não foi diferente. Milhões de braços ociosos vieram bater às portas das cidades, à procura de um futuro melhor ou apenas de um emprego... Sem sucesso, no mais das vezes. Hobsbawn mostra claramente essa tendência:

Em outras palavras, o campesinato, que formara a maioria da raça humana em toda a história registrada, fora tornando supérfluo pela revolução agrícola, mas os milhões não mais necessários na terra eram, no passado, prontamente absorvidos por ocupações necessitadas de mão-de-obra em outros lugares, que exigiam apenas disposição para trabalhar, na adaptação de habilidades rurais, como cavar e erguer paredes, ou capacidade de aprender no trabalho. Que aconteceria aos trabalhadores nessas ocupações quando por sua vez se tornassem desnecessários? [...] Que aconteceria, aliás, aos camponeses do terceiro mundo que ainda fugiram em massa aconteceria, aliás, aos camponeses do terceiro mundo que ainda fugiam em massa de suas aldeias? ${ }^{26}$

Hoje se sabe a resposta a essa pergunta. Mais do que a ociosidade, o que arranca o homem do campo é a falha de perspectiva. "Nesta concepção de mundo, o homem, a cultura, o natural são vistos como recursos a serem usados, bem como as múltiplas dimensões da vida são vistas como recursos a serviço da reprodução do capital".27

A verdade é que nem os problemas urbanos e nem o Direito Urbanístico são novidades. Mesmo assim, causa espanto que uma ciência organizada não consiga ser aplicada em larga escala para o benefício da sociedade. Em 1977, Meireles já tinha uma intensa produção científica organizada a respeito, presente principalmente na sua obra Direito Municipal Brasileiro. Veja-se:

Toda cidade há que ser planejada: a cidade nova, para a sua formação; a cidade implantada, para sua expansão; a cidade velha, para sua renovação. Mas não só o

\footnotetext{
${ }^{26}$ HOBSBAWM, Eric. A era dos extremos. 2 ed. São Paulo: Companhia das Letras, 1995. p. 404.

${ }^{27}$ BECKER, Dinizar Ferminano (Org.). Desenvolvimento sustentável. Necessidade e/ou possibilidade? 4 ed. Santa Cruz do Sul: EDUNISC, 2002. p. 53.

REDESG / Revista Direitos Emergentes na Sociedade Global - www.ufsm.br/redesg v. 1, n. 1, jan.jun/2012
} 
perímetro urbano exige planejamento, como também as áreas de expansão urbana e seus arredores, para que a cidade não venha a ser prejudicada no seu desenvolvimento e na sua funcionalidade pelos futuros núcleos urbanos que tendem a formar-se na sua periferia. ${ }^{28}$

O referido publicista, na ocasião, também comentava a respeito do projeto de uma lei de Desenvolvimento Urbano, que estava a ser elaborado e estudado pela Comissão Nacional de Regiões Metropolitanas e que parece ter sido a inspiração do moderno Estatuto das Cidades, que tinha como objetivos essenciais "a melhoria da qualidade de vida urbana, a distribuição espacial dos contingentes populacionais, o condicionamento do uso do solo e do direito de construir à função social da propriedade e a preservação do meio ambiente". ${ }^{29}$

Assim, embora já de há muito se saiba da necessidade de providências no sentido de organizar as cidades, não havia ainda uma consciência formada a respeito da noção de sustentabilidade.

Não se trata apenas de organizar a cidade de maneira forçada. A cidade sustentável exige a participação voluntária do cidadão, sobretudo no sentido de não tornar sua presença prejudicial ao conjunto da sociedade. Assim, a soma dos instrumentos legais do Poder Público O Plano Diretor, o licenciamento ambiental, a ação de polícia, a intervenção do Ministério Público e do Judiciário - com a participação da sociedade é que permite a sustentabilidade urbana.

De fato, pode-se argumentar que, se o direito urbanístico já é sedimentado; se os instrumentos legais de controle ambiental já existem há muito tempo; se, no entanto, a desorganização das cidades parece crescer, afigura-se que o que ainda pende de implementação é a participação do povo. Mesmo para isso, existem instrumentos adequados! Realmente, o que não existe é o estímulo à efetiva participação. Não se trata da participação na gestão, mas de algo em tese bem mais simples: o exercício do direito à cidade, mas sem deixar que se perca de vista o dever de não agravar os problemas urbanos. O Estatuto da Cidade não trará a solução para tais problemas, já que apenas instrumentaliza o incentivo a uma ética socioambiental, materializada na participação popular.

Hoje sabemos que o pleno direito à cidade inclui o direito à vida com dignidade, à moradia, à alimentação, à saúde, à segurança, ao meio ambiente ecologicamente equilibrado. A efetivação da função social da cidade estabelece-se quando o direito à cidade pode ser exercido

${ }^{28}$ MEIRELLES, Hely Lopes. Direito Municipal Brasileiro. 3. ed. São Paulo: Revista dos Tribunais, 1997. p. 611.

${ }^{29}$ Idem, p. 605.

REDESG / Revista Direitos Emergentes na Sociedade Global - www.ufsm.br/redesg v. 1, n. 1, jan.jun/2012 
em sua plenitude, ou seja, a cidade cumpre sua função social quando os cidadãos possuem os direitos urbanos que são objetivo da política urbana prevista no art. 182 da CF.

A cidade sustentável deve ser uma organização urbana que permita à sua população uma vida de boa qualidade, sendo garantida a presença dos equipamentos urbanos indispensáveis e a prestação dos serviços públicos essenciais. Deve, portanto, manter vigilância sobre os agentes poluidores, mas também proporcionar aqueles direitos há pouco mencionados; manter o controle da expansão urbana, garantindo a instalação dos equipamentos urbanos da ocupação do solo; e, sobretudo, ter em vista a efetivação de uma política agrária e de emprego que evite o afluxo migratório do campo para a cidade e das pequenas para as grandes cidades.

A preocupação ambiental é, portanto, ponto chave dessa construção de cidade sustentável. Não há como pensar a cidade sem a democratização dos espaços e o planejamento ambiental. A lógica dos licenciamentos imobiliários vinculada ao capital financeiro, ou, à influência desse capital na Administração Pública, já trilhou um processo de degradação ambiental massivo e funesto.

É necessário que se pense o meio ambiente enquanto um todo integrado, que se tenha nas cidades, não um locus de meio de reprodução do capital pelo capital, mas um autêntico habitat dessa e das próximas gerações. Essa é a ideia de ecologia profunda, já detalhada na presente pesquisa, que se opõe, frontalmente, ao ambientalismo superficial, o qual na mera reparação do ambiente degradado uma alternativa viável à sustentabilidade, esquecendo-se da prevenção e da necessidade de superação do velho paradigma do desenvolvimento de caráter unicamente econômico. É de Capra a definição dos instrumentos dessa mudança de paradigma:

O gerenciamento ecológico envolve a passagem do pensamento mecanicista para o pensamento sistêmico. Um aspecto essencial dessa mudança é que a percepção do mundo como máquina cede lugar à percepção do mundo como sistema vivo. Essa mudança diz respeito à nossa percepção de natureza, do organismo humano, da sociedade e, portanto, também à percepção de uma organização de negócios. ${ }^{30}$

Dessa forma, a cidade sustentável que se espera, deve ter sempre presente a ideia de rede, percebendo o ambiente urbano a partir dos sistemas vivos que a compõem e não da lógica do capital. Isso só será alcançado com o reconhecimento da importância de se agregar o custo ambiente ao desenvolvimento, deixando-se de lado a mera qualificação econômica, com a

${ }^{30}$ CAPRA, Fritjof et al. Gerenciamento Ecológico. Eco Management. São Paulo: Cultrix, 1999. p. 88.

REDESG / Revista Direitos Emergentes na Sociedade Global - www.ufsm.br/redesg v. 1, n. 1, jan.jun/2012 
constituição sólida de um novo paradigma de vida urbana, que privilegie a qualidade de vida, tão escassa na pós-modernidade.

A cidade acontece nos municípios; trata-se de fenômeno local. Logo, nada mais justo que se reconheça a competência preponderante dos governos municipais quando se trata de assuntos urbanos. Ressalta-se, todavia, que seria equívoco imaginar que transferir pura a simplesmente a responsabilidade da implantação do conceito de sustentabilidade urbana para o município irá solucionar os problemas que nos angustiam. É necessário que se sempre em mente a íntima relação entre o campo e a cidade e as consequências que advêm de uma política equivocada para aquele.

$\mathrm{O}$ art. 182 da CF é a matriz da política urbana brasileira. Esse dispositivo traz, em seu caput, a previsão da competência municipal para a execução de tal política:

Art. 182. A política de desenvolvimento urbano, executada pelo Poder Público municipal, conforme diretrizes gerais fixadas em lei, tem por objetivo ordenar o pleno desenvolvimento das funções sociais da cidade e garantir o bem-estar de seus habitantes.

O Plano Diretor assume um novo papel, uma nova importância. Destinado inicialmente à simples organização material da cidade, regulando o arruamento e o dimensionamento; depois incluindo a distribuição das edificações segundo sua utilização e regulando enfim o uso do solo urbano - passou a instrumento de gerenciamento do território municipal como uma integralidade indissociável de cidades e zonas rurais.

Trata-se do meio de planejamento da sustentabilidade presente e futura. Sua aplicabilidade é imediata, podendo produzir desde logo os efeitos a que se destina, mas sua principal influência está no futuro. Afinal, a maior concentração de problemas organizacionais está no centro de velhas cidades, em áreas com edificação valorização, com custo proibitivo para uma imediata ação baseada na desapropriação. No entanto, à medida que a cidade se renova, as normas do Plano Diretor far-se-ão sentir.

Também cabe ao Município o controle do uso do solo, devendo a autoridade evitar a utilização inadequada dos imóveis urbanos, entendida como aquela que atinge a coletividade prejudicando-a. Do mesmo modo, as áreas de expansão urbana devem ser estabelecidas de modo a não aproximar-se de áreas usadas de modo incompatível com a concentração urbana, como os "distritos industriais".

São iguais competências do município a intensidade do uso do solo, entendida como o percentual de cobertura edificada; a espécie de edificações; e a instalação de empreendimento REDESG / Revista Direitos Emergentes na Sociedade Global - www.ufsm.br/redesg v. 1, n. 1, jan.jun/2012 
que possam desestabilizar as vias de tráfego, que devem ser reguladas de modo que não ocorra o desequilíbrio da área de abrangência do sítio urbano.

Outra importante característica do Estatuto da Cidade diz respeito ao uso social da propriedade. O Município ganha vários instrumentos, com a finalidade de combater a especulação urbana e a subutilização dos terrenos. Além da via fiscal, reforçada pela tributação progressiva e pela recuperação de investimentos que gerem valorização imobiliária, mediante taxas de melhoria, também as áreas de invasão podem ser regularizadas, se de fato a concentração habitacional ali for conveniente. E, como já era previsto, o usucapião urbano ganha novo fôlego, dando ao possuidor a chance de ter como seu o imóvel abandonado, havido de quem dele não necessita.

Acerca da função socioambiental da propriedade, afastada da noção civilista de bem individual, mais próxima da visão pública de bem comum, assevera Jaqueline Maria de Oliveira:

O reconhecimento pelo Ministério Público e pelo Poder Judiciário de uma tese de defesa de interesses ambientais urbanos é um passa à frente no conceito do dever de indenizar. Além de afastar o "fantasma" da desapropriação indireta, instituto processual através do qual já foram obtidas milionárias indenizações, também representa uma evolução na forma de conceber o direito ambiental, como corolário do direito público e, portanto, preponderante sobre o interesse individual. Essa nova tendência jurídica está fazendo atuar a determinação constitucional de que a propriedade "moderna" deve cumprir uma função sócioambiental, impondo um dever de conduta ao particular, que é o de suportar a restrição em benefício da comunidade. ${ }^{31}$

Enfim, o Município recebe a responsabilidade de ser o executor da sustentabilidade urbana - órgão federado deve assumir o papel ativo de organizar o espaço municipal e propiciar a participação dos cidadãos no processo, quer opinando sobre a atuação do ente público, quer se omitindo em praticar condutas lesivas ao ambiente. Além disso, o Município é o responsável pelo famigerado problema da destinação dos resíduos sólidos - essa inevitável “contribuição” de todos com a degradação.

A tarefa é imensa. Muitos municípios alegam a inexistência de pessoal qualificado para as atividades de controle e planejamento ambiental. Outros simplesmente adotam uma conduta passiva ante a insuficiência de fundos que financiem tais atividades. Mas a maioria,

\footnotetext{
${ }^{31}$ SILVA, Jaqueline Maria de Oliveira do Couto. O Direito Ambiental Urbano como excludente do dever de indenizar o Estado. In: AFONSIN, Betânia; FERNANDES, Edésio et al. II Congresso Brasileiro de Direito Urbanístico. Avaliando o Estatuto da Cidade. Porto Alegre: Escola Superior de Direito Municipal, 2002. p. 606.

REDESG / Revista Direitos Emergentes na Sociedade Global - www.ufsm.br/redesg v. 1, n. 1, jan.jun/2012
} 
infelizmente, padece da ignorância e da falsa ilusão de que as pequenas cidades não possuem problemas ambientais.

Para garantir que todos, cidadãos e governos, cumpram com a obrigação sócio-jurídica, mas acima de tudo ética da preservação e da minimização de danos, também existe o necessário controle jurisdicional, dotado de instrumentos processuais adequados e um verdadeiro guardião, a valer tanto quanto as limitações permitem - o Ministério Público.

\section{CONCLUSÃO}

De acordo com a relação entre o desenvolvimento urbano e impacto ambiental, ao longo da história, pode-se constatar que a dinâmica de ascensão e queda das civilizações depende, dentre outras condições verificadas, de sua capacidade de relacionar-se com o meio ambiente de forma sustentável.

A atual civilização, principalmente no que se refere à ocidental a industrial, tem demonstrado, nas últimas décadas, indicadores sempre ascendentes como as taxas de crescimento populacional associadas ao processo de urbanização, ao consumo de energia, à demanda de alimentos e resíduos, ligados ao conceito de desenvolvimento.

A sustentabilidade urbana é considerada um dos maiores desafios ambientais desse final de século, sendo consenso que o acúmulo dos problemas ambientais não reflete apenas na baixa renda. Silva indica que a sustentabilidade é algo dinâmico e particular devido à dificuldade de se enquadrar em postulados científicos, sendo que seu universo está principalmente vinculado a planos de ação que possibilitam adequar os princípios e diretrizes sustentáveis a experiência e/ou situações específicas, com limites temporal e espacial de uma determinada sociedade. ${ }^{32}$

\section{REFERÊNCIAS}

AFONSIN, Betânia; FERNANDES, Edésio et al. Il Congresso Brasileiro de Direito Urbanístico. Avaliando o Estatuto da Cidade. Porto Alegre: Escola Superior de Direito Municipal, 2002.

BECKER, Dinizar Ferminano (Org.). Desenvolvimento sustentável. Necessidade e/ou possibilidade? 4. ed. Santa Cruz do Sul: EDUNISC, 2002.

32 SILVA, S. Indicadores de sustentabilidade urbana, as perspectivas e as limitações da operacinonalização de um referencial sustentável. São Paulo: Universidade Federal, 2000.

REDESG / Revista Direitos Emergentes na Sociedade Global - www.ufsm.br/redesg v. 1, n. 1, jan.jun/2012 
BRITO, Francisco A.; CÂMARA, João B. D. Democratização e gestão ambiental: em busca do desenvolvimento sustentável. Petrópolis: Vozes. 1998.

CANOTILHO, José Joaquim Gomes. Direito constitucional e teoria da constituição. 4. ed. Coimbra: Gráfica de Coimbra. 2000.

CAPRA, Fritjof et al. Gerenciamento Ecológico. Eco Management. São Paulo: Cultrix, 1999

CASTELLS, Manuel. A sociedade em rede. A era da informação: economia, sociedade e cultura. Traduzido por Roneide Venâncio Majer. v. 2. 3. ed. São Paulo: Paz e Terra, 2000.

FREITAS, Vladimir Passos de. Direito Administrativo e Meio Ambiente. 3. ed. Curitiba: Juruá, 2001.

HOBSBAWM, Eric. Era dos extremos: o breve século XX: 1914-1991. 2. ed. São Paulo: Companhia das Letras, 1995.

KINLAW, Denis C. Empresa Competitiva e Ecológica: desempenho sustentável na era ambiental. Traduzido por Lenke Peres Alves de Araújo. São Paulo: Makron Books, 1997.

LEIS, Héctor Ricardo (Org.). Ecologia e Política Mundial. Petrópolis: Vozes, 2001.

LYTE, J.T. Regenerative desing for sustainable development. New York: John Wiley \& Sons, 1994.

MATEO, Ramón Martín. Tratado de derecho ambiental. Madrid: Editoral Trivium. 1991.

MEIRELLES, Hely Lopes. Direito Administrativo Brasileiro. 27. ed. São Paulo: Malheiros, 2002.

PEREIRA, Paulo Afonso Soares. Rios, redes e regiões: a sustentabilidade a partir de um enfoque integrado dos recursos terrestres. Porto Alegre: AGE. 2000. 348 p.

ROCHA, Julio César de Sá da. Função ambiental da cidade: direito ao meio ambiente urbano ecologicamente equilibrado. São Paulo: Juarez de Oliveira, 1999.

SARLET, Ingo Wolfgang. Dignidade da pessoa humana e direitos fundamentais. Porto Alegre: Livraria do Advogado: 2001.

SILVA, José Afonso da. Curso de direito constitucional positivo. 9. ed. rev. atual. São Paulo: Malheiros, 1998.

SILVA, S. Indicadores de sustentabilidade urbana: as perspectivas e as limitações da operacionalização de um referencial sustentável. São Paulo: Universidade Federal, 2000.

Recebido em: 04.07.2012 / Aprovado em: 20.08.2012

REDESG / Revista Direitos Emergentes na Sociedade Global - www.ufsm.br/redesg v. 1, n. 1, jan.jun/2012 